\title{
Substrate particle size-preference of wormlion Vermileo vermileo (Diptera: Vermileonidae) larvae and their interaction with antlions
}

\author{
DUŠAN DEVETAK
}

Department of Biology, Faculty of Natural Sciences and Mathematics, University of Maribor, Koroška cesta 160, 2000 Maribor, Slovenia; e-mail: dusan.devetak@guest.arnes.si

Key words. Wormlion, antlion, Vermileo, Euroleon, substrate particle size, sand, powder

\begin{abstract}
Wormlion larvae are found in substrates consisting of fine sand or powder, implying that they may be able to distinguish between different substrates according to particle size. To estimate the effects of particle size on wormlions, the pit-building decision of the larvae of the wormlion Vermileo vermileo was observed in four substrates consisting of different sand fractions. Wormlion larvae prefer the finest sand fraction with particle size $\leq 230 \mu \mathrm{m}$. When wormlions (Vermileo vermileo) and antlions (Euroleon nostras) are placed in the same container with two different substrates, interspecific predation does not occur. In two-substrate choice tests larvae of the two species show opposite preferences for two substrates offered. While wormlion larvae readily build pits in the finest sand fraction $(\leq 230 \mu \mathrm{m})$, antlion larvae prefer coarser sand (with particle size $230-540 \mu \mathrm{m}$ ). Wormlion preference for the finest sands and powders, and antlion preference for sands of medium particle size was confirmed by field observations. Sand particle size affects the spatial distribution of sand-dwelling insect larvae and thus may reduce conflicts between heterosp ecifics.
\end{abstract}

\section{INTRODUCTION}

Wormlions (Diptera: Vermileonidae) are of great interest to biologists. It is the only dipteran family known whose larvae capture prey by constructing pits in loose soil (Wheeler, 1930; Ludwig et al., 1996, 2001). Larvae of antlions (Neuroptera: Myrmeleontidae) similarly use funnel-shaped pits to capture prey. In contrast to wormlions their predatory behaviour is extensively studied. Only a few antlion species build pitfall traps, and this is considered to be the most specialized strategy for capturing prey within the Myrmeleontidae (Gepp \& Hölzel, 1989; Mansell, 1996, 1999). Pit-building antlions wait at the bottom of the pit for prey. The antlions are generally located at the pit centre but may move away from the centre over time (Fertin \& Casas, 2006). They feed on small arthropods that slide into the pit. The antlion larva detects its prey from a distance of a few centimetres by sensing the vibrations that the prey generates during locomotion (Devetak et al., 2007; Mencinger-Vračko \& Devetak, 2008).

The antlion pit both funnels prey to the jaws of the larvae (Lucas, 1982) and retards the escape of the prey (Griffiths, 1980; Devetak, 2005). When the prey arrives at the bottom of the pit, the antlion attempts to capture it and insert its jaws. If the prey is not bitten at the first attempt, or if the prey evades the larva and tries to climb out of the pit, the antlion tosses sand with violent flicks of its head. This causes miniature landslides, which carry the prey back to the predator. Antlion larvae select sites for pit construction based on habitat suitability (Lucas, 1986; Farji-Brener et al., 2008), sand particle size (Allen \& Croft, 1985; Loiterton \& Magrath, 1996; Botz et al., 2003; Devetak et al., 2005; Matsura et al., 2005), prey availability (Griffiths, 1980; Sharf \& Ovadia, 2006), level of disturbance (Gotelli, 1993) and abundance of conspecifics (Matsura \& Takano, 1989; Linton et al., 1991).

The larvae of Vermileo vermileo (L.), which is widely distributed in the Mediterranean, construct their pits in dry substrates sheltered from rain. Wormlion larvae feed on small arthropods that slide into the pit (Wheeler, 1930). Larval morphology and classification of wormlions is described in detail by Ludwig et al. (1996, 2001). Parts of the body of Vermileonidae larvae are specialized for prey capture, including the mouthparts and pseudopodium (Ludwig et al., 1996, 2001). The pseudopodium is probably involved in the mechanical detection and seizure of prey. An abdominal comb with a transverse row of long spines on the posterior part of the larval body is used to anchor it in the sand (Ludwig et al., 2001).

Field observations support the assumption that Vermileo larvae prefer to construct pits in substrates of fine sand and avoid coarser sand. They only exceptionally cooccur with antlion larvae, which use a similar pit-building predatory strategy. A common pit-building antlion species occurring in similar habitats is Euroleon nostras (Geoffroy in Fourcroy). When found in wormlion habitats antlion larvae occur at low densities.

The pit-building predatory behaviour of Vermileo vermileo makes it interesting from an ecophysiology perspective. Wormlions occur in substrates consisting of the finest sand or powder, implying that like antlions (Botz et al., 2003; Devetak et al., 2005) they may be able to distinguish between different substrate particle sizes. In this study, the pit-building decision of the wormlion Vermileo vermileo larvae was observed in substrates consisting of different sand fractions. Two questions were addressed: (i) Are wormlions capable of discriminating between sand fractions of different particle sizes? (ii) How are worm- 
lions and antlions distributed in two substrates differing in particle sizes?

\section{MATERIAL AND METHODS}

Wormlion larvae Vermileo vermileo (L.) originated from Baška Voda (Dalmatia, Croatia), August 2006. Antlion larvae Euroleon nostras (Geoffroy in Fourcroy) were collected in the surroundings of Maribor, Slovenia, from June to August 2006. Samples of sand taken from natural habitats were analysed in the laboratory using a standard sieving method (see below).

The wormlion larvae were kept in the laboratory, at room temperature, in plastic containers $(60 \times 45 \times 10 \mathrm{~cm})$ filled with substrate from natural habitats. Substrate particle size was $\leq 230$ $\mu \mathrm{m}$. Antlions were kept in plastic containers filled with sieved quartz sand (Kema Puconci d.d., Slovenia) with a particle size of $10-500 \mu \mathrm{m}$. The moisture content of the sand was less than $1.5 \%$ by weight.

The prey supplied to both predators were workers of the ant species Lasius fuliginosus (Latreille) and L. emarginatus (Olivier). Feeding occurred daily and one ant was placed in each pit.

Mechanical analysis of particle size distribution of substrates from natural habitats was conducted using sieves of standard DIN 1170 and DIN 1171 (for details of the method see Devetak et al., 2007). Substrates from the following wormlion locations were analyzed: Baška Voda (Croatia), Osp and Piran (both in Slovenia) and the following antlion locations: Dekani, Piran and Rižana (all in Slovenia).

\section{The effect of substrate particle size}

To obtain fractions of different particle sizes, comminuted quartz sand (Kema Puconci d.d.; grain sizes $0-4 \mathrm{~mm}$ ) was sieved. The fractions used in the experiments were: (i) fraction with grains $\leq 230 \mu \mathrm{m}$ (G1), (ii) 230-540 $\mu \mathrm{m}$ (G2), (iii) 540-1000 $\mu \mathrm{m}$ (G3), and (iv) 1000-1540 $\mu \mathrm{m}$ (G4). To avoid cannibalism prior to treatment each wormlion larva was kept singly in a container. The number of pits built was expressed as a percentage of the number of pits constructed.

\section{Four-substrate choice test}

The hypothesis that wormlions are capable of distinguishing between substrate types was tested by giving wormlions the choice of building a pit in substrates of one of four particle-sizes. Twenty cylindrical plastic containers (diameter $12 \mathrm{~cm}$, depth $5.5 \mathrm{~cm}$ ) were partitioned using cardboard into four quadrants of equal size. Each quadrant was filled carefully with $100 \mathrm{ml}$ of substrate of a certain particle-size. The following were used in the experiment: particle size $\leq 230 \mu \mathrm{m}(\mathrm{G} 1)$,
230-540 $\mu \mathrm{m}$ (G2), 540-1000 $\mu \mathrm{m}$ (G3) and 1000-1540 $\mu \mathrm{m}$ (G4). The cardboard was then carefully removed. A wormlion was placed in the centre of the area. The particle size in the quadrant in which a pit was built was recorded and pit diameter measured after $6,12,48$ and $96 \mathrm{~h}$. In this experiment 20 wormlions were tested simultaneously.

\section{Two-substrate choice test}

Antlion and wormlion larvae had the choice of building pits in substrates with one of two particle-sizes. Plastic containers measuring $20 \times 15 \times 10.5 \mathrm{~cm}$ were partitioned using cardboard into two halves. Each half was filled with $500 \mathrm{ml}$ of sand of a certain particle size. The cardboard was then removed. The particle sizes used in the experiment were $\leq 230 \mu \mathrm{m}$ (G1) and 230-540 $\mu \mathrm{m}(\mathrm{G} 2)$. Five antlions and five wormlions were placed simultaneously on the border between the two substrates. The position of an animal without a pit and particle-size of the substrate with a pit were noted after $48 \mathrm{~h}$. This was replicated ten times. To avoid pseudoreplication, a different wormlion and antlion was used in each replicate.

\section{RESULTS}

\section{Field observations on wormlion habitats}

The habitats of larval wormlions and antlions were observed in Slovenia (Dekani, Osp, Piran, Rižana) and Croatia (Rovinj, Baška Voda). Larvae constructed their pits in loose dry sand or powder in small cracks in walls of old buildings or below rocky overhangs on coastal cliffs. Sieving the substrates revealed that wormlions readily build pits in substrates composed of a mixture of powders (with particle size $\leq 60 \mu \mathrm{m}$ ) and fine sand $(60-110 \mu \mathrm{m})$ (Table 1).

For wormlion the preferred substrate had a particle size $\leq 110 \mu \mathrm{m}$ (comprising 25 to $57 \mathrm{w} \%$ of sample) and for antlion it was significantly coarser sand with a particle size of $230-540 \mu \mathrm{m}$ (comprising 45 to $50 \mathrm{w} \%$ of sample) (Table 1).

The number of wormlions pits recorded in the coastal habitats near Baška Voda varied from 16 to $38 / 100 \mathrm{~cm}^{2}$. Pit-building antlion larvae usually do not occur in wormlion communities. In cracks in the walls in Rovinj wormlion and antlion (Euroleon nostras) larvae did not occur together. In Baška Voda only two antlion larvae were found in a community of ca. 200 wormlions.

TABLE 1 . The weight $\%(\mathrm{w} \%)$ substrate particle size distribution in six natural habitats of wormlions and antlions.

\begin{tabular}{|c|c|c|c|c|c|c|}
\hline \multirow{3}{*}{ Sand fraction } & \multicolumn{6}{|c|}{ Location of habitat } \\
\hline & \multicolumn{3}{|c|}{ Vermileo vermileo } & \multicolumn{3}{|c|}{ Euroleon nostras } \\
\hline & Baška Voda & Osp & Piran & Dekani & Piran & Rižana \\
\hline$\leq 60 \mu \mathrm{m}$ & 24.46 & 14.36 & 8.16 & 1.03 & 3.38 & 14.62 \\
\hline $60-110 \mu \mathrm{m}$ & 32.25 & 17.05 & 17.42 & 9.73 & 11.08 & 5.22 \\
\hline $110-230 \mu \mathrm{m}$ & 20.3 & 11.54 & 17.83 & 19.91 & 18.69 & 13.41 \\
\hline $230-540 \mu \mathrm{m}$ & 13.99 & 36.11 & 35.61 & 51.95 & 45.38 & 50.44 \\
\hline $540-1000 \mu \mathrm{m}$ & 3.6 & 7.15 & 6.43 & 7.32 & 6.77 & 4.9 \\
\hline $1000-1540 \mu \mathrm{m}$ & 2.2 & 6.83 & 4.82 & 3.78 & 3.46 & 4.59 \\
\hline $1540-2200 \mu \mathrm{m}$ & 1 & 6.96 & 4.82 & 3.08 & 3.3 & 3.21 \\
\hline$\geq 2200 \mu \mathrm{m}$ & 2.2 & 0 & 4.91 & 3.2 & 7.94 & 3.61 \\
\hline Sum & $100 \mathrm{w} \%$ & $100 \mathrm{w} \%$ & $100 \mathrm{w} \%$ & $100 \%$ & $100 \mathrm{w} \%$ & $100 \mathrm{w} \%$ \\
\hline
\end{tabular}




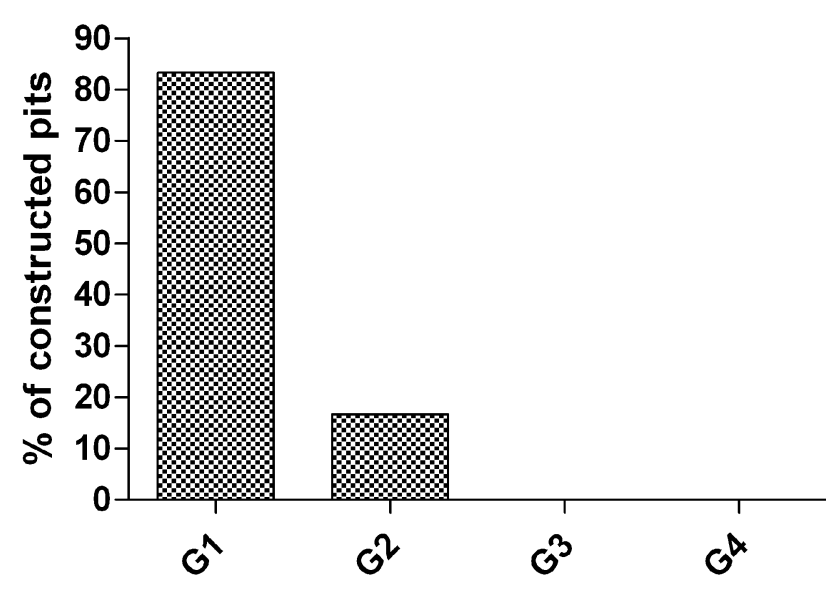

Fig. 1. The percentage of pits constructed in each of four substrates by Vermileo larvae after $48 \mathrm{~h}$. X axis: substrate particle sizes: G1: $\leq 230 \mu \mathrm{m}, \mathrm{G} 2: 230-540 \mu \mathrm{m}$; G3: 540-1000 $\mu \mathrm{m}$; G4: $1000-1540 \mu \mathrm{m}$.

\section{The effect of substrate particle size on pit-building}

Four-substrate choice test

To avoid interaction between conspecifics, each wormlion was placed singly in a container with four different substrates. Of the 20 Vermileo larvae tested, 13 built pits in one particular substrate after $6 \mathrm{~h}$ and 20 after $12 \mathrm{~h}$.

The most preferred substrate for pit-building was that made up of the finest sand fraction, G1 (particle size $\leq 230 \mu \mathrm{m})$. After $6 \mathrm{~h}, 11$ larvae constructed pits in $\mathrm{G} 1$, one in $\mathrm{G} 2$, one at the junction of $\mathrm{G} 1$ and $\mathrm{G} 2$, and seven did not build pits. After $12 \mathrm{~h}$, the number of pits in G1 was 15 , in G2 3 and two larvae built pits at the junction of $\mathrm{G} 1$ and G2. The same proportion of pits were constructed in each substrate after $48 \mathrm{~h}$ (Fig. 1) and 96 h, respectively. No pits were built in the two substrates with the coarser sand fractions (G3 and G4). Vermileo larvae, therefore, prefer to build their pits in the finest sand (G1, particle size $\leq 230 \mu \mathrm{m}$ ) (chi-square test of equal numbers of pits in

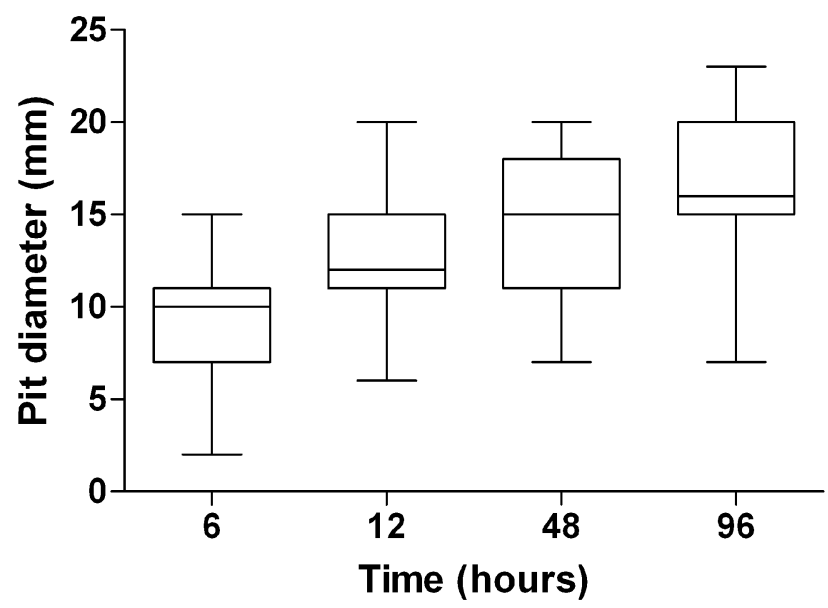

Fig. 2. The change in the diameter of the pits constructed by Vermileo larvae in the finest sand fraction (particle size $\leq 230$ $\mu \mathrm{m})$ over a four-day period. Lines across boxes indicate medians, lower and upper boundaries first and third quartiles, and adjacent whiskers lowest and highest values.

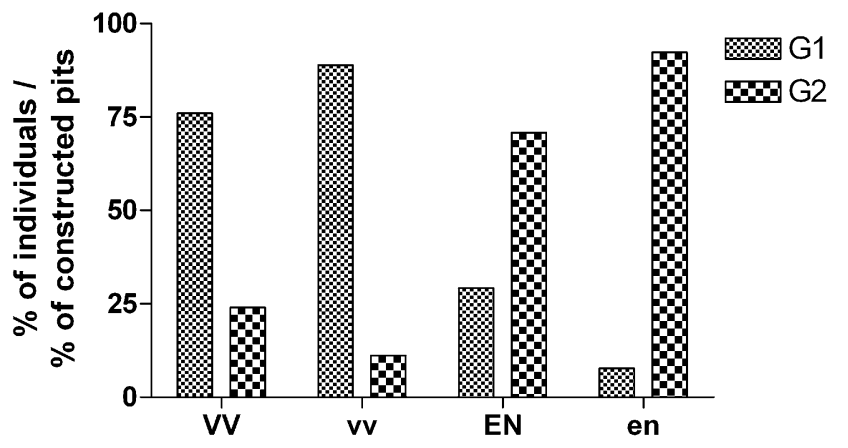

Fig. 3. Percentage of individuals constructing pits in each of two-substrates after 48 h. Legend: Vermileo vermileo: VV individuals, vv - pits. Euroleon nostras: EN - individuals, en pits.

each fraction; $\mathrm{t}=48 \mathrm{~h}, \chi^{2}=34$, d.f. $=3, \mathrm{P}<0.0001, \mathrm{n}=$ 18 larvae).

Wormlion larvae constructed smallest pits after $6 \mathrm{~h}$ (mean pit diameter \pm standard deviation was $9.5 \pm 3.8$ $\mathrm{mm}$ ) in the sandy substrate with a particle size $\leq 230 \mu \mathrm{m}$ (G1) (Fig. 2) and larger pits after $96 \mathrm{~h}$ (mean pit diameter \pm standard deviation was $16.5 \pm 4.3 \mathrm{~mm}$ ).

Two-substrate choice test and interspecific interactions

When larvae of the two species were placed at the border between the two sandy substrates (G1 and G2), they selected different substrates (Fig. 3). Minima, medians and maxima of the preferred substrates of the larvae (10 observations) after $48 \mathrm{~h}$ are listed in Table 2.

Vermileo larvae preferred the fine sand substrate (G1). Of the 50 wormlion larvae tested, 38 preferred to G1 and 12 G2. Euroleon larvae showed the opposite preference. 34 antlion larvae preferred G2 and 14 G1. Two antlions were eaten by conspecifics and no interspecific predation was recorded. Yates' continuity corrected chi-square test revealed that the preference of Vermileo larvae for the fine and that of Euroleon larvae for the coarser sandy substrates was statistically significant (two-sided test; $\chi^{2}$ $=19.73, \mathrm{df}=1, \mathrm{P}<0.0001$, alpha $<0.05)$.

Number of pits constructed in each substrate after $48 \mathrm{~h}$ is given in Table 3 . Vermileo larvae readily built pits in G1; 32 pits were built there and only 4 in G2. Euroleon larvae showed the opposite preference, with 24 pits constructed in G2 and 2 in G1. Yates' continuity corrected chi-square test revealed that the preference of Vermileo larvae for fine and that of Euroleon larvae for constructing pits in coarse sand were statistically significant

TABLE 2. Number of individuals in each sand fraction recorded after $48 \mathrm{~h}$ based on 10 replicates of the two-substrate choice test. Vermileo: $\mathrm{n}=5$ larvae per replicate; Euroleon: $\mathrm{n}=$ 5 larvae per replicate; G1: $\leq 230 \mu \mathrm{m}, \mathrm{G} 2: 230-540 \mu \mathrm{m}$.

\begin{tabular}{lcclccc}
\hline & \multicolumn{2}{c}{ Vermileo vermileo } & & \multicolumn{2}{c}{ Euroleon nostras } \\
\cline { 2 - 3 } \cline { 5 - 6 } & $\mathrm{G} 1$ & $\mathrm{G} 2$ & & $\mathrm{G} 1$ & $\mathrm{G} 2$ \\
\hline Minimum & 2 & 0 & & 0 & 3 \\
Median & 4 & 1 & & 1 & 3 \\
Maximum & 5 & 3 & & 2 & 5 \\
\hline
\end{tabular}


TABLE 3. Number of pits in each sand fraction recorded after $48 \mathrm{~h}$ based on 10 replicates of the two-substrate choice test. Vermileo: $\mathrm{n}=5$ larvae per replicate; Euroleon: $\mathrm{n}=5$ larvae per replicate; G1: $\leq 230 \mu \mathrm{m}, \mathrm{G} 2: 230-540 \mu \mathrm{m}$.

\begin{tabular}{lcclccc}
\hline & \multicolumn{2}{c}{ Vermileo vermileo } & & \multicolumn{2}{c}{ Euroleon nostras } \\
\cline { 2 - 3 } \cline { 5 - 6 } & $\mathrm{G} 1$ & $\mathrm{G} 2$ & & $\mathrm{G} 1$ & $\mathrm{G} 2$ \\
\hline Minimum & 2 & 0 & & 0 & 1 \\
Median & 3 & 0 & & 0 & 3 \\
Maximum & 5 & 2 & & 1 & 4 \\
\hline
\end{tabular}

(two-sided test; $\chi^{2}=36.98, \mathrm{df}=1, \mathrm{P}<0.0001$, alpha $<$ $0.05)$.

\section{DISCUSSION}

The use of funnel-shaped pits for catching prey has evolved independently in two groups of psammophilous insects, antlions and wormlions. Although the building of the trap is energy-consuming, it has advantages in that it reduces the amount of energy expended in hunting and chasing prey. The spatial distribution and activity of these sand-dwelling arthropods is influenced by physical characters of sandy substrates, such as humidity, temperature and particle size.

A powder is defined as a granular medium made of particles less than $100 \mu \mathrm{m}$ in diameter (Brown \& Richards, 1970; Duran, 2000). Measurements of particle sizes of substrates originating from wormlion natural habitats (Baška Voda, Osp, Piran) revealed that wormlion larvae prefer the finest sands and powders (particle sizes $\leq 110$ $\mu \mathrm{m})$.

In antlions, the importance of substrate particle size in site selection by the larvae and adults have been studied (Youthed \& Moran, 1969; Kitching, 1984; Allen \& Croft, 1985; Loiterton \& Magrath, 1996; Botz et al., 2003; FarjiBrener, 2003; Devetak et al., 2005; Matsura et al., 2005). Antlion larvae of the European species Euroleon nostras prefer sands with a particle size of 230-540 $\mu \mathrm{m}$ (Devetak et al., 2005, 2007).

In both, antlions and wormilons the negative effect of increasing substrate particle size on pit-building can be explained in terms of the limitations of the mechanical strength of the larvae. As Kitching (1984) speculates for antlion larvae, large sand particles are probably more difficult to handle, and thus more time is required to build functional pits. Particle size affects pit diameter and thus directly affects capture success (Farji-Brener, 2003; Devetak et al., 2005). Sand particle size may increase capture success by affecting the capability of prey to escape (Allen \& Croft, 1985). In antlion assemblages, capture success is clearly correlated with pit density (Griffiths, 1986; Devetak, 2005; Sharf \& Ovadia, 2006). Moreover, large pits are constructed in finer sand and are better buffered against changes in temperature than smaller pits (Marsh, 1987).

Distribution of larval populations of Myrmeleon bore is probably determined mainly by the oviposition of adult females rather than migration of larvae (Matsura et al., 2005). It is supposed that the selection of oviposition sites by adult females could be the most important factor gov- erning the spatial distribution of pits in the field not only of antlions but also wormlions. However, the oviposition behaviour of Myrmeleon crudelis and M. immaculatus may not necessarily determine the spatial distribution of pits (Gotelli, 1993).

In the two-substrate choice test larvae of wormlions (Vermileo) and antlions (Euroleon) showed opposite preferences for two sandy substrates. While wormlion larvae readily built pits in the fine sand $(\leq 230 \mu \mathrm{m})$, antlion larvae preferred the coarse sand (with particle size 230-540 $\mu \mathrm{m})$. For wormlions and antlions, the opposite preference for sands of different particle sizes indicated by the experiments was confirmed by field observations. Sieving of sands and powders from natural habitats revealed that wormlions prefer substrates consisting mainly of fine grains (particle size $\leq 110 \mu \mathrm{m}$ ) and antlions of medium grains (particle size 230-540 $\mu \mathrm{m}$ ).

When two species were placed in the same container with two different substrates, interspecific predation did not occur, but cannibalism in antlions did. In natural habitats cannibalism in antlions is often recorded (Devetak, 2000) and other insect orders also prey on antlions. Recently it was discovered that therevid larvae (Diptera: Therevidae) feed on the larva of antlions (Gepp \& Klausnitzer, 2005). In the field it seems that antlions avoid areas inhabited by wormlions and vice versa. This preferences of these species for different substrates does not necessarily imply avoidance behaviour. They may simply prefer different substrates independent of the presence of heterospecifics.

Foragers use various biotic and abiotic cues to help them locate resources (Bell, 1991) and there is currently much interest in habitat selection and competition (Rosenzweig, 1991). Some species change their preferred habitat when a competitive species is present (Abramsky et al., 1991). Predation commonly occurs between animals of dissimilar size, while competition occurs between animals of similar size. This study is the first on the interspecific competition between wormlions and antlions. Antlions prefer sandy substrates of medium particle size and wormlions those of powders and sands of the smallest particle size. Because both, wormlions and antlions occur in the same habitats and their body sizes vary, their habitat partitioning based on substrates with different particle sizes probably enables them to avoid contact and thus predation.

ACKNOWLEDGEMENT. I thank two anonymous reviewers for valuable criticism and helpful suggestions on an early version of the manuscript. This study was supported by a research grant from the Slovene Ministry of High Education, Science and Technology (Grant No. P1-0078 Biodiversity).

\section{REFERENCES}

Abramsky Z., Rosenzweig M.L. \& Pinshow B. 1991: The shape of a gerbil isocline measured using principles of optimal habitat selection. Ecology 72: 329-340.

Allen G.R. \& CROFT D.B. 1985: Soil particle size and the pit morphology of the Australian ant-lions Myrmeleon diminutus and M. pictifrons (Neuroptera: Myrmeleontidae). Aust. J. Zool. 33: 863-874. 
Bell W.J. 1991: Searching Behaviour. Chapman and Hall, New York, xii +358 pp.

Botz J.T., Loudon C., Barger J.B., Olafsen J.S. \& Steeples D.W. 2003: Effects of slope and particle size on ant locomotion: implications for choice of substrate by antlions. J. Kans. Entomol. Soc. 76: 426-435.

Brown R.L. \& Richards J.C. 1970: Principles of Powder Mechanics. Pergamon Press, Oxford, New York, $221 \mathrm{pp}$.

Devetak D. 2000: Competition in larvae of two European antlion species (Neuroptera: Myrmeleontidae). J. Neuropterol. 3: $51-60$.

DevetaK D. 2005: Effects of larval antlions Euroleon nostras (Neuroptera, Myrmeleontidae) and their pits on the escapetime of ants. Physiol. Entomol. 30: 82-86.

DeVeTAK D., ŠPernjaK A. \& JANŽEKovič F. 2005: Substrate particle size affects pit building decision and pit size in the antlion larvae Euroleon nostras (Neuroptera: Myrmeleontidae). Physiol. Entomol. 30: 158-163.

Devetak D., Mencinger-VračKo B., Devetak M., Marhl M. \& ŠPERNJAK A. 2007: Sand as a medium for transmission of vibratory signals of prey in antlions Euroleon nostras (Neuroptera: Myrmeleontidae). Physiol. Entomol. 32: 268-274.

Duran J. 2000: Sands, Powders, and Grains. An Introduction to the Physics of Granular Materials. Springer, New York, 214 pp.

FARJI-BRENER A.G. 2003: Microhabitat selection by antlion larvae, Myrmeleon crudelis: effect of soil particle size on pittrap design and prey capture. J. Insect Behav. 16: 783-796.

Farji-Brener A.G., Carvajal D., Gei M.G., Olano J. \& SánCHEZ J.D. 2008: Direct and indirect effects of soil structure on the density of an antlion larva in a tropical dry forest. Ecol. Entomol. 33: 183-188.

Fertin A. \& CASAS J. 2006: Efficiency of antlion trap construction. J. Exp. Biol. 209: 3510-3515.

Gepp J. \& Hölzel H. 1989: Ameisenlöwen und Ameisenjungfern - Myrmeleonidae. Ziemsen Verlag, Wittenberg Lutherstadt, $108 \mathrm{pp}$.

Gepp J. \& Klausnitzer B. 2005: Therevidenlarven (Dipt., Therevidae) als Prädatoren des Ameisenlöwen Euroleon nostras (Neuroptera, Myrmeleontidae). Entomol. Nachr. Ber. 49: 25-27.

Gotelli N.J. 1993: Ant lion zones: causes of high-density predator aggregations. Ecology 74: 226-237.

Griffiths D. 1980: The feeding biology of ant-lion larvae: prey capture, handling and utilization. J. Anim. Ecol. 49: 99-125.

Griffiths D. 1986: Pit construction by ant-lion larvae: a costbenefit analysis. J. Anim. Ecol. 55: 39-57.

KiTCHING R.L. 1984: Some biological and physical determinants of pit size in larvae of Myrmeleon pictifrons Gerstaecker
(Neuroptera: Myrmeleontidae). J. Aust. Entomol. Soc. 23: 179-184.

Linton M.C., Crowley P.H., Williams J.T., Dillon P.M., Aral H., Strohmeier K.L. \& Wood C. 1991: Pit relocation by antlion larvae: a simple model and laboratory test. Evol. Ecol. 5: 93-104.

Loiterton S.J. \& Magrath R.D. 1996: Substrate type affects partial prey consumption by larvae of the antlion Myrmeleon acer (Neuroptera: Myrmeleontidae). Austr. J. Zool. 44: 589-597.

LUCAS J.R. 1982: The biophysics of pit construction by antlion larvae (Myrmeleon, Neuroptera). Anim. Behav. 30: 651-664.

LUCAS J.R. 1986: Antlion pit construction and kleptoparasitic prey. Fla Entomol. 69: 702-710.

Ludwig P., Melzer R.R. \& Ehrhardt V. 2001: Larval morphology and classification of wormlions (Diptera, Vermileonidae). Mitt. Dtsch. Ges. Allg. Angew. Entomol. 13: 89-94.

Ludwig P., Smola U. \& Melzer R.R. 1996: Die Mundwerkzeuge des Wurmlöwen Vermileo vermileo L. und ihre Funktion (Diptera, Vermileonidae). Nachrbl. Bayer. Entomol. 45: 9-14.

Mansell M.W. 1996: Predation strategies and evolution in antlions (Insecta: Neuroptera: Myrmeleontidae). In Canard M., Aspöck H. \& Mansell M.W. (eds): Pure and Applied Research in Neuropterology. Sacco, Toulouse, pp. 161-169.

Mansell M.W. 1999: Evolution and success of antlions (Neuropterida: Neuroptera: Myrmeleontidae). Stapfia 60 138: 49-58.

MARSH A.C. 1987: Thermal responses and temperature tolerance of a desert ant-lion larva. J. Therm. Biol. 12: 295-300.

Matsura T. \& TaKano H. 1989: Pit-relocation of antlion larvae in relation to their density. Res. Popul. Ecol. 31: 225-234.

Matsura T., Yamaga Y. \& IтоH M. 2005: Substrate selection for pit making and oviposition in an antlion, Myrmeleon bore Tjeder, in terms of sand particle size. Entomol. Sci. 8: 347-353.

Mencinger-VračKo B. \& DeVetak D. 2008: Orientation of the pit-building antlion larva Euroleon (Neuroptera, Myrmeleontidae) to the direction of substrate vibrations caused by prey. Zoology 111: 2-8.

RosenZWEIG M.L. 1991: Habitat selection and population interactions: the search for mechanism. Am. Nat. 137: 5-28.

SCHARF I. \& OvADIA O. 2006: Factors influencing site abandonment and site selection in a sit-and-wait predator: A review of pit-building antlion larvae. J. Insect Behav. 19: 197-218.

WheELer W.M. 1930: Demons of the Dust. Kegan Paul, Trench, Trubner \& Co., London, 378 pp.

Youthed G.J. \& Moran V.C. 1969: Pit construction by myrmeleontid larvae. J. Insect Physiol. 15: 867-875.

Received January 31, 2008; revised and accepted February 29, 2008 